\title{
Steiner $\mu$ Distance in Fuzzy Graphs with Application
}

\author{
G.Priscilla Pacifica, J.Jenit Ajitha
}

\begin{abstract}
In this article we define Steiner and upper Steiner $\mu$ distances in connected fuzzy graphs by combining the notion of Steiner distance with $\mu$ distance and proved that both are metric. Also based on $\mu$ length, eccentricity, radius, diameter, diametric vertex, eccentric vertex, centre, convexity, self-centred graphs are introduced for both Steiner and upper Steiner $\mu$ distances . Some common characteristic properties are analysed and relation between Steiner and upper Steiner $\mu$ distances are discussed with an application. A model result is given for transport network.2010 AMS Classification: 05C72, 05C12

Keywords : Fuzzy Steiner $\mu$-distance, upper Fuzzy Steiner $\mu$-distance, fuzzy Steiner $\mu_{\mathrm{k}}$-eccentricity, upper fuzzy Steiner $\mu_{\mathrm{k}}$-eccentricity.
\end{abstract}

\section{INTRODUCTION}

We often face unpredictability in many of our real life problems. So we need to consider fuzziness in every field. Rosenfeld developed the postulation of fuzzy graph theory in 1975. Although a fuzzy graph is similar in structure to that of a crisp graph, it better describes a real situation than a crisp graph and has some special characteristics. Steiner distance in crisp graphs and its properties were described in [3] and [10]. The properties of fuzzy graphs and their applications in various fields are studied from [1], [2], [4], [6], [7] and [8]. Some new distance parameters are introduced and examined in [5] and [9]. Here we introduce new parameters Steiner $\mu$ distance and upper Steiner $\mu$ distance in fuzzy graphs.

\section{PRILIMINARIES}

Through out this article we consider only the connected fuzzy graphs $\mathrm{G}$ without loops and assume that $\mathrm{V}$ is finite and nonempty. Also we use the terms 'nodes' for vertices and 'arcs' for edges.

Definition 2.1 If G is a connected graph with $n$ nodes and $S$ is a subset of $V(G)$, then the Steiner distance among the nodes of $\mathrm{S}$ is defined as the minimum size among all connected minimal sub graphs whose node sets contain S. These sub graphs are called Steiner trees of $\mathrm{S}$.

Definition 2.2 The Steiner interval, $\mathrm{I}_{\mathrm{G}}(\mathrm{S})$ or $\mathrm{I}(\mathrm{S})$, of a set $\mathrm{S}$ is defined by $\mathrm{I}_{\mathrm{G}}(\mathrm{S})=\{\mathrm{w} \in \mathrm{V}(\mathrm{G}) / \mathrm{w}$ lies on a Steiner tree for $\mathrm{S}$ in G\}

Revised Manuscript Received on April 26, 2020

* Correspondence Author

Dr.G.Priscilla Pacifica*, Department of Mathematics, St.Mary's College(Autonomous), Thoothukudi, Tamilnadu, South India.

J.Jenit Ajitha, Department of Mathematics, St.Mary's College(Autonomous), Thoothukudi affiliated under Manonmaniam Sundaranar University, Tirunelveli, South India.

(c) The Authors. Published by Blue Eyes Intelligence Engineering and Sciences Publication (BEIESP). This is an open access article under the CC BY-NC-ND license (http://creativecommons.org/licenses/by-nc-nd/4.0/)
Definition 2.3 Let $G$ be a connected crisp graph and $S$, the subset of nodes $V(G)$, if $I(S)=V(G)$ then $S$ is called a Steiner set.

Definition 2.4 A fuzzy graph is denoted by $G(V, \sigma, \mu)$ where $\mathrm{V}$ is a node set, $\sigma$ is a fuzzy subset of $\mathrm{V}$ and $\mu$ is a fuzzy relation on $\sigma$ which satisfies $\mu(\mathrm{u}, \mathrm{v}) \leq \sigma(\mathrm{u}) \wedge \sigma(\mathrm{v}) \forall \mathrm{u}, \mathrm{v} \in \mathrm{V}$.

Definition 2.5 For a connected fuzzy graph, if $\mathrm{P}$ is the path: $\mathrm{u}_{0}, \mathrm{u}_{1}, \ldots, \mathrm{u}_{\mathrm{n}}$ then the $\mu$-length of $\mathrm{P}, \mathrm{l}(\mathrm{P})$ is the sum of reciprocals of arc weights. That is $\mathrm{I}(\mathrm{P})=\sum_{\mathrm{i}=1}^{\mathrm{n}} \frac{1}{\mu\left[\mathrm{u}_{\overline{\mathrm{i}}-1}\left(\mathrm{u}_{\overline{\mathrm{i}}}\right)\right.}$. If $\mathrm{n}$ $=0$, then $\mathrm{l}(\mathrm{P})=0$. and $\mu$ - distance is the smallest $\mu$-length of any $\mathrm{u}^{-} \mathrm{v}$ path.

\section{FUZZY STEINER $\mu$ DISTANCE}

Definition 3.1 Let $G(V, \sigma, \mu)$ be a connected fuzzy graph with $\mathrm{n}$ nodes. The Steiner $\mu$ distance between any two nodes of a non-empty set $\mathrm{S} \subseteq \mathrm{V}(\mathrm{G})$ is defined as the minimum sum of reciprocals of arc weights of minimal connected fuzzy sub graphs containing S. These fuzzy sub graphs are called fuzzy Steiner trees for $S$. The fuzzy Steiner $\mu$ distance of $S$ is denoted by $d_{\mu G}(S)$ (or) $d_{\mu S}(u, v)$ where $u$ and $v$ are nodes in $\mathrm{S}$. For $\mathrm{k}=2,3, \ldots . \mathrm{n}$ we define the following parameters of fuzzy Steiner $\mu$-distance.

Definition 3.2 The fuzzy Steiner $\mu_{\mathrm{k}}$-eccentricity $\mathrm{e}_{\mu_{\mathrm{k}} \mathrm{G}}(\mathrm{u})$ of any node $\mathrm{u}$ is given below $\mathrm{e}_{\mu_{\mathrm{k}} \mathrm{G}}(\mathrm{u})=\max \left\{\mathrm{d}_{\mu \mathrm{S}}(\mathrm{u}, \mathrm{v}) / \mathrm{S} \subseteq \mathrm{V}(\mathrm{G}),|\mathrm{S}|=\right.$ $\mathrm{k} \& \mathrm{u}, \mathrm{v} \in \mathrm{S}\}$

Definition 3.3 The fuzzy Steiner $\mu_{k}$ radius of any node $u$ in $G$ is

$\mathrm{r}_{\mu_{\mathrm{k}} \mathrm{G}}(\mathrm{G})=\min \left\{\mathrm{e}_{\mu_{\mathrm{k}} \mathrm{G}}(\mathrm{u}) / \mathrm{u} \in \mathrm{V}(\mathrm{G})\right\}$

Definition 3.4 The fuzzy Steiner $\mu_{k}$ diameter of a node $u$ in $\mathrm{V}(\mathrm{G})$ is

$\operatorname{diam}_{\mu_{\mathrm{k}} \mathrm{G}}(\mathrm{G})=\max \left\{\mathrm{e}_{\mu_{\mathrm{k}} \mathrm{G}}(\mathrm{u}) / \mathrm{u} \in \mathrm{V}(\mathrm{G})\right\}$

Definition 3.5 A node $u$ is a fuzzy Steiner $\mu_{\mathrm{k}}$ diametral node (or) peripheral node if

$\mathrm{e}_{\mu_{\mathrm{k}} \mathrm{G}}(\mathrm{u})=\operatorname{diam}_{\mu_{\mathrm{k}} \mathrm{G}}(\mathrm{G})$

Definition 3.6 The fuzzy Steiner $\mu_{k}$ centre $C_{\mu_{k}}(G)$ of a fuzzy graph $G$ is the fuzzy subgraph induced by the nodes $u$ of $\mathrm{V}(\mathrm{G})$ with $e_{\mu_{\mathrm{k}} \mathrm{G}}(\mathrm{u})=\mathrm{r}_{\mu_{\mathrm{k}} \mathrm{G}}(\mathrm{G})$. These nodes are called fuzzy Steiner $\mu_{\mathrm{k}}$ central nodes (or) fuzzy Steiner $\mu_{\mathrm{k}}$ eccentric nodes.

Definition 3.7 The fuzzy Steiner $\mu_{\mathrm{k}}$ median of $\mathrm{G}$ is the fuzzy subgraph of $G$ induced by the nodes of minimum fuzzy Steiner $\mu_{\mathrm{k}}$ distance in $\mathrm{G}$.

Definition 3.8 The fuzzy average Steiner $\mu_{\mathrm{k}}$ distance of a graph G, is defined as the average of the fuzzy Steiner H-distances of all k-subsets of $\mathrm{V}$ (G).

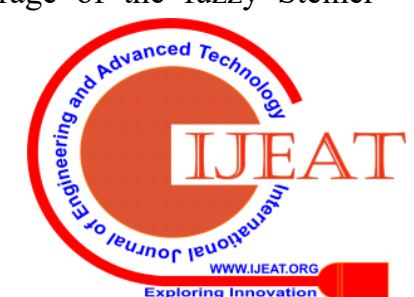




\section{Steiner $\boldsymbol{\mu}$ Distance in Fuzzy Graphs with Application}

Definition 3.9 A subset of nodes $S$ is called fuzzy Steiner $\mu_{k}$ convex if each vertex in any Steiner fuzzy tree of $S$ is contained in S.

Definition 3.10 A fuzzy graph $\mathrm{G}(\mathrm{V}, \sigma, \mu)$ is said to be fuzzy Steiner $\mu_{\mathrm{k}}$ self-centred graph if the fuzzy Steiner $\mu_{\mathrm{k}}$ eccentricity of every node of the graph is the same (or) if fuzzy Steiner $\mu_{\mathrm{k}}$ radius and fuzzy Steiner $\mu_{\mathrm{k}}$ diameter of the graph are equal.

Definition 3.11 The fuzzy Steiner $\mu_{\mathrm{k}}$ interval, $\mathrm{I}_{\mu \mathrm{G}}(\mathrm{S})$ of a set $S \subseteq \mathrm{V}(\mathrm{G})$ with cardinality $\mathrm{k}$ is defined by $\mathrm{I}_{\mathrm{\mu G}}(\mathrm{S})=\{\mathrm{w} \in \mathrm{V}$ (G) / w lies on a Steiner fuzzy tree for $S$ in $G$ \}

Definition 3.12 Let $G$ be a connected fuzzy graph and $S$, a subset of nodes $V(G)$, if $I_{\mu G}(S)=V(G)$, then $S$ is called a Steiner fuzzy set.

Example 1 For example consider the following fuzzy graph

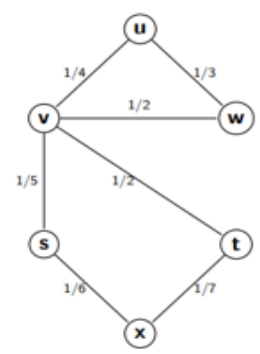

Figure 1

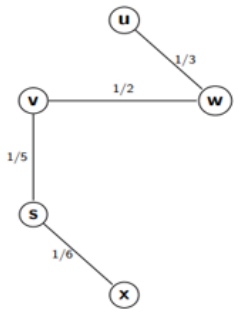

$\mathrm{T}_{1}$

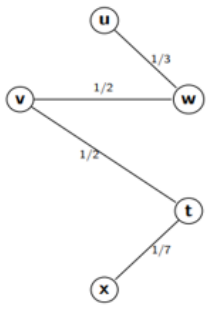

$\mathrm{T}_{2}$

Figure 2

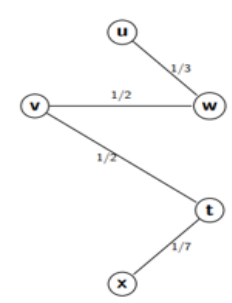

Figure 3

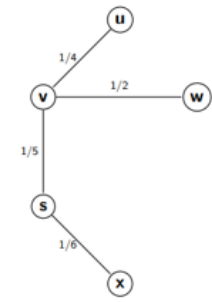

$\mathrm{T}_{3}$

\begin{tabular}{|l|l|l|}
\hline $\mathrm{S}_{2}$ & $\{\mathrm{u}, \mathrm{v}, \mathrm{s}, \mathrm{x}, \mathrm{t}\}$ & 17 \\
\hline $\mathrm{S}_{3}$ & $\{\mathrm{u}, \mathrm{v}, \mathrm{s}, \mathrm{w}, \mathrm{t}\}$ & 12 \\
\hline $\mathrm{S}_{4}$ & $\{\mathrm{u}, \mathrm{v}, \mathrm{s}, \mathrm{w}, \mathrm{x}\}$ & 16 \\
\hline $\mathrm{S}_{5}$ & $\{\mathrm{v}, \mathrm{w}, \mathrm{s}, \mathrm{x}, \mathrm{t}\}$ & 17 \\
\hline $\mathrm{S}_{6}$ & $\{\mathrm{u}, \mathrm{s}, \mathrm{w}, \mathrm{x}, \mathrm{t}\}$ & 16 \\
\hline
\end{tabular}

Table 3

\begin{tabular}{|c|c|c|}
\hline Nodes & Fuzzy Steiner $\mu_{5}$-eccentricities & ${ }^{{ }^{e}}{ }_{\mu_{5} \mathrm{G}}$ \\
\hline $\mathrm{u}$ & $\max \{14,17,12,16,16\}$ & 17 \\
\hline $\mathrm{v}$ & $\max \{14,17,12,16,17\}$ & 17 \\
\hline $\mathrm{W}$ & $\max \{14,12,16,16,17\}$ & 17 \\
\hline $\mathrm{s}$ & $\max \{17,12,16,16,17\}$ & 17 \\
\hline $\mathrm{t}$ & $\max \{14,17,12,16,17\}$ & 17 \\
\hline $\mathrm{x}$ & $\max \{14,17,16,16,17\}$ & 17 \\
\hline
\end{tabular}

The fuzzy Steiner $\mu$ distance of $S$ is,

$\mathrm{d}_{\mathrm{uG}}(\mathrm{S})=\min \{14,14,15\}=14$. Here $\mathrm{T}_{1}$ and $\mathrm{T}_{2}$ are minimum Steiner fuzzy trees for $\mathrm{S}$.

Take $\mathrm{k}=5$. Let $\mathrm{S}_{1}=\{\mathrm{u}, \mathrm{v}, \mathrm{w}, \mathrm{x}, \mathrm{t}\}$ then $\mathrm{d}_{\mu \mathrm{G}}\left(S_{1}\right)=14$.The minimum Steiner fuzzy tree for $S_{1}$ is given in fig 3 .

Similarly the fuzzy Steiner $\mu$ distances of $S_{1}, S_{2}, S_{3}, S_{4}, S_{5}, S_{6}$ are given in table 2 .

The fuzzy Steiner $\mu_{5}$-eccentricities are given in table 3 .

The fuzzy Steiner $\mu_{5}$ eccentricity of every node is same. Hence the above fuzzy graph is fuzzy Steiner $\mu_{5}$ self centered. The fuzzy average Steiner $\mu_{5}$ distance is $\frac{14+17+12+16+16+17}{5}=18.4$.

\section{PROPERTIES OF FUZZY STEINER $\mu$ DISTANCE}

A. Theorem The fuzzy Steiner $\mu$-distance of a non-empty set of nodes $S$ on a connected fuzzy graph $G,\left(V, \mathrm{~d}_{\mathrm{us}}(\mathrm{u}, \mathrm{v})\right)$ where $\mathrm{u}, \mathrm{v} \in \mathrm{S}$ is a metric.(i.e)

i) $\mathrm{d}_{\mathrm{us}}(\mathrm{u}, \mathrm{v}) \geq 0$ for all $\mathrm{u}, \mathrm{v}$ and for all subsets $\mathrm{S} \subseteq \mathrm{V}(\mathrm{G})$

ii) $d_{\mu s}(u, v)=0$ iff $u=v$

iii) $\mathrm{d}_{\mu \mathrm{s}}(\mathrm{u}, \mathrm{v})=\mathrm{d}_{\mu \mathrm{s}}(\mathrm{v}, \mathrm{u})$

iv) $d_{\mu s}(u, w) \leq d_{\mu s_{1}}(u, v)+d_{\mu s_{2}}(v, w) \quad$ where $\mathrm{u} \in \mathrm{S} \& \mathrm{~S}_{1}, \mathrm{w} \in \mathrm{S} \& \mathrm{~S}_{2}, \mathrm{v} \in \mathrm{S}_{1} \& \mathrm{~S}_{2}$ and $\mathrm{S}_{1}, \mathrm{~S}_{2}$ and $\mathrm{S}$ are subsets of $\mathrm{V}(\mathrm{G})$ such that $\left|\mathrm{S}_{1}\right|=\left|\mathrm{S}_{2}\right|=|\mathrm{S}|=\mathrm{k}$

Proof :The first three results (i),(ii) and (iii) are true from the definition of Steiner $\mu$-distance of $S$. It remains to show that the triangle inequality holds. Let $S_{1}$ and $S_{2}$ be two non-empty subsets of $\mathrm{V}(\mathrm{G})$ such that $\left|\mathrm{S}_{1}\right|=\left|\mathrm{S}_{2}\right|=|\mathrm{S}|=\mathrm{k}$. Clearly the result is true if any two of the nodes are equal. Now choose distinct nodes $\mathrm{u}, \mathrm{v}$ and $\mathrm{w}$ as in the hypothesis. The Steiner $\mu$-distance $\mathrm{d}_{\mu \mathrm{G}}(\mathrm{S})$ is the same for any two nodes in $\mathrm{S}$. Also since $\left|S_{1}\right|=\left|S_{2}\right|=|S|=k$, the Steiner $\mu$-distance of $S$ is at most $\mathrm{d}_{\mu s_{1}}(\mathrm{u}, \mathrm{v})+\mathrm{d}_{\mu s_{2}}(\mathrm{v}, w)$. Hence fuzzy Steiner $\mu$-distance is a metric.

B. Remark The triangle inequality holds only if

C. Observation For a fuzzy graph with $n$ nodes, a Steiner fuzzy set which has less than $n$ vertices is not fuzzy Steiner $\mu_{k}$

\begin{tabular}{|l|l|c|}
\hline \multicolumn{2}{|c|}{ Node set } & Fuzzy Steiner $\mu$ distance $\left(\mathrm{d}_{\mathrm{\mu G}}\right)$ \\
\hline $\mathrm{S}_{1}$ & $\{\mathrm{u}, \mathrm{v}, \mathrm{w}, \mathrm{x}, \mathrm{t}\}$ & 14 \\
\hline
\end{tabular}
$\left|S_{1}\right|=\left|S_{2}\right|=|S|$.

convex where $k=2,3, \ldots, n$

Table 2

Table 1

\begin{tabular}{|c|c|c|}
\hline $\begin{array}{c}\text { Steiner fuzzy } \\
\text { trees }\end{array}$ & fuzzy $\mu$-distance & Total \\
\hline $\mathrm{T}_{1}$ & $3+2+5+6$ & 14 \\
\hline $\mathrm{T}_{2}$ & $3+2+2+7$ & 14 \\
\hline $\mathrm{T}_{3}$ & $4+2+5+6$ & 15 \\
\hline
\end{tabular}

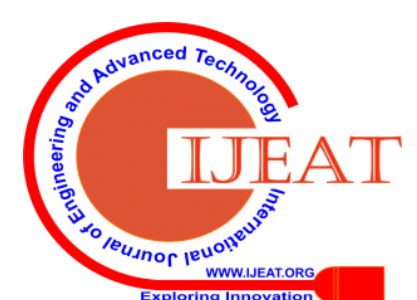


D. Observation Obviously $\mathrm{e}_{\mu_{\mathrm{K}} \mathrm{G}}(\mathrm{u})>\mathrm{d}_{\mathrm{\mu s}}(\mathrm{u}, \mathrm{v})$ for all nodes $u, v$ in $\mathrm{V}(\mathrm{G})$ where $\mathrm{d}_{\mathrm{\mu s}}(\mathrm{u}, \mathrm{v})$ is with respect to any non-empty fuzzy subset $\mathrm{S} \subseteq \mathrm{V}(\mathrm{G})$ and $k=2,3, \ldots . n$ where $n$ denotes the number of nodes.

E. Theorem For a connected fuzzy graph $G$ with $n$ nodes where $\mathrm{n} \geq 3$ and $k=3,4, \ldots, n$, if $u$ and $v$ are distinct nodes then $\left|\mathrm{e}_{\mathrm{H}_{\mathrm{K}} \mathrm{G}}(\mathrm{u})-\mathrm{e}_{\mathrm{H}_{\mathrm{K}} \mathrm{G}}(\mathrm{v})\right| \leq \mathrm{d}_{\mathrm{\mu}}(\mathrm{u}, \mathrm{v})$ where $\mathrm{S} \subseteq \mathrm{V}(\mathrm{G})$ with $|S|=k$ and $\mathrm{u}, \mathrm{v} \in \mathrm{S}$.

Proof: Let $\mathrm{v}$ be a node. The fuzzy Steiner $\mu_{\mathrm{k}}$ eccentricity of $\mathrm{v}$ is the maximum fuzzy Steiner $\mu$-distance of any non-empty set of nodes with cardinality $\mathrm{k}$ that contains $\mathrm{v}$ say $\mathrm{S}$. Let $\mathrm{w}$ be a node with such maximum fuzzy Steiner $\mu$-distance with respect to the set $S$ with cardinality k.(i.e) $\mathrm{e}_{\mathrm{H}_{\mathrm{k}} \mathrm{G}}(\mathrm{v})=\mathrm{d}_{\mu \mathrm{S}}(\mathrm{w}, \mathrm{v})$. Suppose $\mathrm{u}$ is a node other than $\mathrm{v}$ in S. Since fuzzy Steiner $\mu$-distance is a metric, by triangle inequality we have

$$
\mathrm{e}_{\mu_{\mathrm{k}} \mathrm{G}}(\mathrm{v})=\mathrm{d}_{\mu \mathrm{s}}(\mathrm{w}, \mathrm{v}) \leq \mathrm{d}_{\mu \mathrm{s}}(\mathrm{w}, \mathrm{u})+\mathrm{d}_{\mu \mathrm{s}}(\mathrm{u}, \mathrm{v}) \text {. Also }
$$

$\mathrm{d}_{\mu \mathrm{s}}(\mathrm{w}, \mathrm{u}) \leq \mathrm{e}_{\mu \mathrm{k}} \mathrm{G}(\mathrm{u})$.

Hence $e_{\mu_{\mathrm{K}} \mathrm{G}}(\mathrm{v}) \leq \mathrm{e}_{\mu_{\mathrm{K}} \mathrm{G}}(\mathrm{u})+\mathrm{d}_{\mu \mathrm{s}}(\mathrm{u}, \mathrm{v})$.

$\Rightarrow \mathrm{e}_{\mu_{\mathrm{k}} \mathrm{G}}(\mathrm{v})-\mathrm{e}_{\mu_{\mathrm{k}} \mathrm{G}}(\mathrm{u}) \leq \mathrm{d}_{\mu S}(\mathrm{u}, \mathrm{v})$. Similarly if we interchange the nodes $\mathrm{u}$ and $\mathrm{v}$, we get $e_{\mu_{K} G} G(u)-e_{\mu_{k} G}(v) \leq d_{\mu s}(u, v)$.From these two inequalities we obtain the required inequality.

F. Theorem For a connected fuzzy graph $G$,

$\left.\mathrm{r}_{\mathrm{\mu}_{\mathrm{K}} \mathrm{G}}(\mathrm{G}) \leq \operatorname{diam}_{\mathrm{\mu}_{\mathrm{K}} \mathrm{G}} \mathrm{G}\right) \leq 2 \mathrm{r}_{\mu_{\mathrm{k}} \mathrm{G}}(\mathrm{G})$

Proof: It follows from definition that $\mathrm{r}_{\mathrm{H}_{\mathrm{K}} \mathrm{G}}(\mathrm{G}) \leq \operatorname{diam}_{\mathrm{H}_{\mathrm{K}} \mathrm{G}}(\mathrm{G})$ for any $\mathrm{k}$. Let $\mathrm{u}$ and $\mathrm{w}$ be two nodes with $\mathrm{d}_{\mu S}(\mathrm{u}, \mathrm{w})=\operatorname{diam}_{\mu_{\mathrm{K}} \mathrm{G}}(\mathrm{G})$ where $\mathrm{S}$ is a non-empty set of nodes with $|\mathrm{S}|=\mathrm{k}$. Let $\mathrm{v}$ be a node with $\mathrm{r}_{\mathrm{H}_{\mathrm{K}} \mathrm{G}}(\mathrm{G})=\mathrm{e}_{\mathrm{\mu}_{\mathrm{K}} \mathrm{G}}(\mathrm{v})$. Since fuzzy Steiner $\mu$-distance is a metric by triangle inequality, we have

$\operatorname{diam}_{\mu_{\mathrm{K}} \mathrm{G}}(\mathrm{G})=\mathrm{d}_{\mathrm{\mu S}}(\mathrm{u}, \mathrm{w}) \leq \mathrm{d}_{\mathrm{\mu s}_{1}}(\mathrm{u}, \mathrm{v})+\mathrm{d}_{\mathrm{\mu}_{\mathrm{2}}}(\mathrm{v}, \mathrm{w})$ where $\left|\mathrm{S}_{1}\right|=\left|\mathrm{S}_{2}\right|=|\mathrm{S}|=\mathrm{k}, \quad \mathrm{S}_{1} \quad$ and $\quad \mathrm{S}_{2}$ are chosen such that $\mathrm{u}, \mathrm{v} \in S_{1} \& \mathrm{v}, \mathrm{w} \in S_{2}$, Now from observation $\mathrm{D}$ $\mathrm{d}_{\mu \mathrm{S}_{1}}(\mathrm{u}, \mathrm{v}) \leq \mathrm{e}_{\mu_{\mathrm{K}} \mathrm{G}}(\mathrm{v})$ and $\mathrm{d}_{\mu \mathrm{s}_{2}}(\mathrm{v}, \mathrm{w}) \leq \mathrm{e}_{\mu_{\mathrm{K}} \mathrm{G}}(\mathrm{v})$. Thus $\operatorname{diam}_{\mathrm{R}_{\mathrm{K}} \mathrm{G}}(\mathrm{G}) \leq \mathrm{e}_{\mathrm{\mu}_{\mathrm{R}} \mathrm{G}}(\mathrm{v})+\leq \mathrm{e}_{\mathrm{H}_{\mathrm{R}} \mathrm{G}}(\mathrm{v})=\mathrm{r}_{\mathrm{p}_{\mathrm{R}} \mathrm{G}}(\mathrm{G})+$ $\mathrm{r}_{\mathrm{P}_{\mathrm{K}} \mathrm{G}}(\mathrm{G})=2 \mathrm{r}_{\mathrm{H}_{\mathrm{K}} \mathrm{G}}(\mathrm{G})$

Hence the result.

G. Observation For any node u of a connected fuzzy graph $G$, diam ${ }_{\mathrm{H}_{\mathrm{K}} \mathrm{G}}(\mathrm{G})-\mathrm{e}_{\mathrm{H}_{\mathrm{K}} \mathrm{G}}(\mathrm{u}) \geq \mathrm{m}$ where $\mathrm{m}$ is any arbitrary non negative real number.

If $G$ is a connected fuzzy graph then for node $u$, $\left.\mathrm{r}_{\mu_{\mathrm{K}} \mathrm{G}}(\mathrm{G}) \leq \mathrm{e}_{\mu_{\mathrm{K}} \mathrm{G}} \mathrm{G}\right) \leq \operatorname{diam}_{\mu_{\mathrm{k}} \mathrm{G}}(\mathrm{G})$

diam $_{\mu_{\mathrm{K}} \mathrm{G}}(\mathrm{G})-\mathrm{e}_{\mu_{\mathrm{k}} \mathrm{G}}(\mathrm{u}) \geq m$ where $m \geq 0$

H. Theorem For a connected fuzzy graph $G$, if $S, S_{1}$ and $S_{2}$ are non empty subsets of vertices, then

$\left|\mathrm{d}_{\mu \mathrm{S}_{1}}(\mathrm{u}, \mathrm{x})-\mathrm{d}_{\mu \mathrm{S}_{2}}(\mathrm{x}, \mathrm{v})\right| \leq \mathrm{d}_{\mu \mathrm{s}}(\mathrm{u}, \mathrm{v})$ where $\mathrm{u} \in \mathrm{S} \& \mathrm{~S}_{1}$, $v \in S \& S_{2}, x \in S_{1} \& S_{2}$.

The above theorem follows from triangle inequality in theorem A

\section{Theorem If a connected fuzzy graph $G$ is Steiner}

$\mu_{\mathrm{k}}$-self-centred, then every node of $G$ is fuzzy Steiner $\mu_{\mathrm{k}}$ eccentric.

Proof: Suppose G is a connected fuzzy graph which is Steiner $\mu_{\mathrm{k}}$-self-centred. Then for every node G, the fuzzy Steiner $\mu_{\mathrm{k}}$ eccentricity is the same. Let $\mathrm{v}$ be the fuzzy Steiner $\mu_{\mathrm{k}}$ eccentric node of u.(i.e) $e_{\mu_{k} G}(u)=d_{\mu s}(u, v)$ where $S$ is a non-empty set with cardinality k. Now since G is fuzzy Steiner $\mu_{\mathrm{k}}$-self-centred we have,

$e_{\mu_{k} G}(u)=e_{\mu_{k} G}(v)=d_{\mu s}(u, v)$. Hence $u$ is a fuzzy Steiner $\mu_{\mathrm{k}}$ eccentric node of $\mathrm{v}$. Therefore every node is fuzzy Steiner $\mu_{\mathrm{k}}$ eccentric.

\section{J. Remark If a connected fuzzy graph $G$ is Steiner}

$\mu_{\mathrm{k}}$-self-centred and for every node $u$ such that $u$ is a Steiner $\mu_{\mathrm{k}}$ eccentric node of another node $v$, then $v$ should be one of the Steiner $\mu_{\mathrm{k}}$ eccentric nodes of $u$.

\section{FUZZY UPPER STEINER $\mu$ DISTANCE}

Definition 5.1 For a connected fuzzy graph with n nodes the fuzzy upper Steiner $\mu$-distance between any two nodes of a non-empty set $S \subseteq V(G)$ is defined as the maximum sum of reciprocals of arc weights of minimal connected fuzzy sub graphs containing $\mathrm{S}$. The corresponding steiner fuzzy tree is called the maximum steiner fuzzy tree of $S$. The fuzzy upper Steiner $\mu$ distance of $S$ is denoted by $D_{\mu G}(S)$ (or) $D_{\mu s}(u, v)$ where $u$ and $v$ are nodes in $S$. For $k=2,3, \ldots . n$, we define the following parameters of fuzzy upper Steiner $\mu$-distance.

Definition 5.2 The fuzzy upper Steiner $\mu_{\mathrm{k}}$-eccentricity $\mathrm{E}_{\mu_{\mathrm{k}} G}(\mathrm{u})$ for a node $\mathrm{u}$ in $\mathrm{V}(\mathrm{G})$ is

$$
\mathrm{E}_{\mu_{\mathrm{k}} \mathrm{G}}(\mathrm{u})=\max \left\{\mathrm{D}_{\mu \mathrm{S}}(\mathrm{u}, \mathrm{v}) / \mathrm{S} \subseteq \mathrm{V}(\mathrm{G}),|\mathrm{S}|=\right.
$$

$\mathrm{k} \& \mathrm{u}, \mathrm{v} \in \mathrm{S}\}$

Definition 5.3 The fuzzy upper Steiner $\mu_{k}$ radius of any node $\mathrm{u}$ in $\mathrm{G}$ is given by

$\mathrm{R}_{\mu_{\mathrm{k}} \mathrm{G}}(\mathrm{G})=\min \left\{\mathrm{E}_{\mu_{\mathrm{k}} \mathrm{G}}(\mathrm{u}) / \mathrm{u} \in \mathrm{V}(\mathrm{G})\right\}$

Definition 5.4 The fuzzy upper Steiner $\mu_{k}$ diameter of a node $\mathrm{u}$ in $\mathrm{V}(\mathrm{G})$ is given by

$\operatorname{DIAM}_{\mu_{\mathrm{K}} \mathrm{G}}(\mathrm{G})=\max \left\{\mathrm{E}_{\mu_{\mathrm{K}} \mathrm{G}}(\mathrm{u}) / \mathrm{u} \in \mathrm{V}(\mathrm{G})\right\}$

Definition 5.5 A node u is a fuzzy upper Steiner $\mu_{k}$ diametral node (or) peripheral node if

$\mathrm{E}_{\mu_{\mathrm{k}} G}(\mathrm{u})=\operatorname{DIAM}_{\mu_{\mathrm{k}} G}(\mathrm{G})$

Definition 5.6 The fuzzy upper Steiner $\mu_{k}$ centre $C_{\mu_{k}}$ (G) of a connected fuzzy graph $G$ is the fuzzy subgraph induced by the nodes u of $\mathrm{V}(\mathrm{G})$ with $E_{\mu_{\mathrm{k}} \mathrm{G}}(\mathrm{u})=\mathrm{R}_{\mu_{\mathrm{k}} \mathrm{G}}(\mathrm{G})$. The node u is called fuzzy upper Steiner $\mu_{k}$ central node (or) fuzzy upper Steiner $\mu_{k}$ eccentric node.

Definition 5.7 The fuzzy upper Steiner $\mu_{k}$ median of a connected fuzzy graph $G$ is the fuzzy subgraph of $G$ induced by the nodes of minimum fuzzy upper Steiner $\mu$ distance of a k-subset in G.

Definition 5.8 The fuzzy upper average Steiner $\mu_{k}$ distance of a graph $\mathrm{G}$, is defined as the average of the fuzzy upper Steiner $\mu$-distances of all k-subsets of V (G).

Definition 5.9 A fuzzy graph G is said to be fuzzy upper Steiner $\mu_{\mathrm{k}}$ self-centred graph if the fuzzy upper Steiner $\mu_{\mathrm{k}}$ eccentricity of every node of the graph is the same (or) if

Published By:

Blue Eyes Intelligence Engineering

\& Sciences Publication

(C) Copyright: All rights reserved.

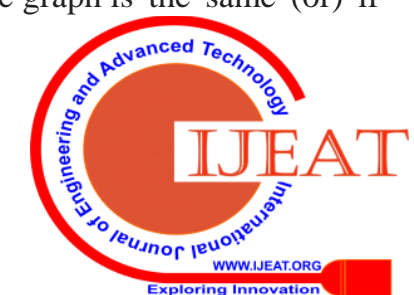




\section{Steiner $\boldsymbol{\mu}$ Distance in Fuzzy Graphs with Application}

fuzzy upper Steiner $\mu_{\mathrm{k}}$ radius and fuzzy upper Steiner $\mu_{\mathrm{k}}$ diameter of the graph are equal.

Example 2 Let us consider the following fuzzy graph

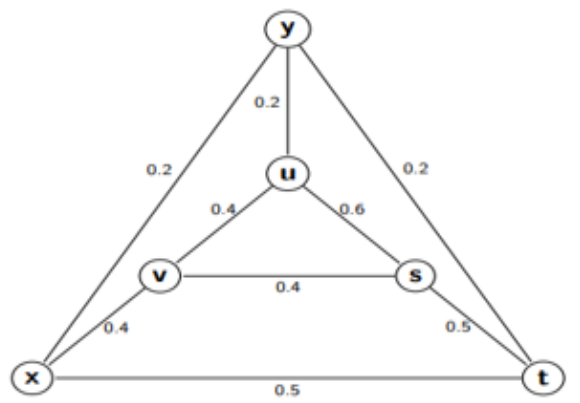

Figure 4
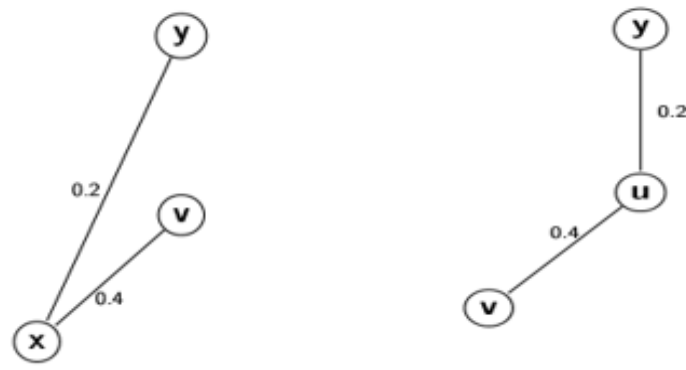

Figure 5
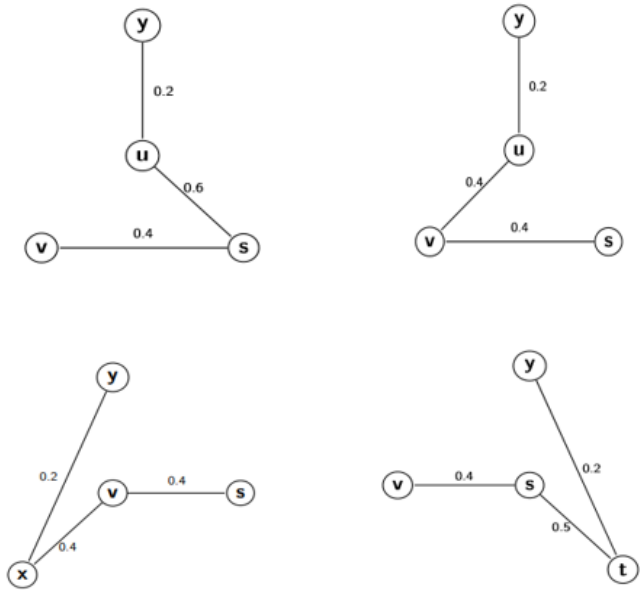

Figure 6

\begin{tabular}{|c|l|l|}
\hline Nodes & Fuzzy upper Steiner $\mu_{2}$-eccentricities & $\mathrm{E}_{\mu_{2} \mathrm{G}}$ \\
\hline $\mathrm{u}$ & $\max \{1,6,5,2.5,10,10\}$ & 10 \\
\hline $\mathrm{s}$ & $\max \{1,6,2.5,7,2,5\}$ & 7 \\
\hline $\mathrm{v}$ & $\max \{2.5,2.5,5,4.5,7.5\}$ & 7.5 \\
\hline $\mathrm{y}$ & $\max \{5,7,5,5,7.5\}$ & 7.5 \\
\hline $\mathrm{t}$ & $\max \{2,10,2,5,4.5\}$ & 10 \\
\hline $\mathrm{x}$ & $\max \{2,5,5,5,10\}$ & 10 \\
\hline
\end{tabular}

Table 4

\begin{tabular}{|c|l|l|}
\hline Nodes & Fuzzy upper Steiner $\mu_{\mathrm{g}}$-eccentricities & $\mathrm{E}_{\mu_{3} \mathrm{G}}$ \\
\hline $\mathrm{u}$ & $\max \{4.1,7.5,7,6,7.5,12,10,3,6,12.5,5,10\}$ & 12.5 \\
\hline $\mathrm{S}$ & $\max \{4.1,10,7,6,7,4.5,7.5,4,10,3.6,5\}$ & 10 \\
\hline $\mathrm{V}$ & $\max \{4.1,10,9.5,7.5,4.5,4.5,7.5,5,12.5,5\}$ & 12.5 \\
\hline
\end{tabular}

Table 5

\begin{tabular}{|l|l|l|}
\hline $\mathrm{y}$ & $\max \{10,10,7.5,10,7,7.6,7.5,10,9.5,10\}$ & 10 \\
\hline $\mathrm{t}$ & $\max \{9.5,10,7,4.5,12,4,4.5,3.6,12.5,10\}$ & 12.5 \\
\hline $\mathrm{x}$ & $\max \{10,7.5,12,4,4.5,10,7.5,10,5,5\}$ & 12 \\
\hline
\end{tabular}

In the fuzzy graph given in fig 4 , for a 2-subset $S=\{v, y\}$ the Steiner fuzzy trees given in fig 5 are both minimum and maximum Steiner fuzzy trees. The fuzzy Steiner $\mu$-distance and fuzzy upper Steiner $\mu$-distance of $\mathrm{S}$ are same.

$\mathrm{d}_{\mu \mathrm{G}}(\mathrm{S})=\mathrm{D}_{\mu \mathrm{G}}(\mathrm{S})=\frac{1}{0.2}+\frac{1}{0.4}=7.5$

The fuzzy upper Steiner $\mu_{2}$ eccentricities for 2-subsets are given in table 4.

The fuzzy upper Steiner $\mu_{2}$ radius is

$\mathrm{R}_{\mu_{\mathrm{k}} \mathrm{G}}(\mathrm{G})=\min \{10,7,7.5,7.5,10,10\}=7$

The fuzzy upper Steiner $\mu_{2}$ diameter is

$\operatorname{DIAM}_{\mu_{k} G}(G)=\max \{10,7,7.5,7.5,10,10\}=10$

The only fuzzy upper Steiner $\mu_{2}$ eccentric node is s.

Fuzzy upper Steiner $\mu_{2}$ diametral nodes are $\mathrm{u}$, $\mathrm{x}$ and $\mathrm{t}$.

For a 3-subset, $\mathrm{T}=\{\mathrm{s}, \mathrm{v}, \mathrm{y}\}$ the Steiner fuzzy trees are given in fig 6 . The fuzzy Steiner $\mu$ distance and fuzzy upper Steiner $\mu$ -distance of $\mathrm{T}$ are

$\mathrm{d}_{\mu \mathrm{G}}(\mathrm{T})=\frac{1}{0.2}+\frac{1}{0.4}+\frac{1}{0.6}=9.1$,

$\mathrm{D}_{\mu \mathrm{G}}(\mathrm{S})=\frac{1}{0.2}+\frac{1}{0.4}+\frac{1}{0.4}=10$

The fuzzy upper Steiner $\mu_{3}$ eccentricities for $\mathrm{k}=3$ subsets are given in table 5 .

The fuzzy upper Steiner $\mu_{3}$ radius is

$\mathrm{R}_{\mu_{\mathrm{g}} \mathrm{G}}(\mathrm{G})=\min \{10,12.5,12\}=10$

The fuzzy upper Steiner $\mu_{3}$ diameter is

$\operatorname{DIAM}_{\mu_{3} G}(\mathrm{G})=\max \{10,12.5,12\}=12.5$

Fuzzy upper Steiner $\mu_{3}$ eccentric nodes are s and y.

Fuzzy upper Steiner $\mu_{3}$ diametral nodes are $\mathrm{u}, \mathrm{v}$ and t.

\section{PROPERTIES OF FUZZY UPPER STEINER $\mu$ DISTANCE}

The fuzzy upper Steiner $\mu$ distance has the same characteristic properties as that of fuzzy Steiner $\mu$ distance.The fuzzy upper Steiner $\mu$-distance of a non-empty set of nodes $S \subseteq V(G)$ on a connected fuzzy graph $\mathrm{G}(\mathrm{V}, \sigma, \mu),\left(\mathrm{V}, \mathrm{D}_{\mu \mathrm{s}}(\mathrm{u}, \mathrm{v})\right)$ where $\mathrm{u}, \mathrm{v} \in \mathrm{S}$ is a metric.(i.e).The triangle inequality holds only if $\left|S_{1}\right|=\left|S_{2}\right|=|S|$.

A. For $\mathrm{n} \geq 3$ and $k=3,4, \ldots$, n, if $u$ and $v$ are distinct nodes then $\left|\mathrm{E}_{\mu_{\mathrm{k}} \mathrm{G}}(\mathrm{u})-\mathrm{E}_{\mu_{\mathrm{k}} \mathrm{G}}(\mathrm{v})\right| \leq \mathrm{D}_{\mu \mathrm{s}}(\mathrm{u}, \mathrm{v})$ where $\mathrm{S} \subseteq \mathrm{V}(\mathrm{G})$ with $|S|=k$ and $\mathrm{u}, \mathrm{v} \in \mathrm{S}$.

B. $\mathrm{E}_{\mu_{\mathrm{k}} \mathrm{G}}(\mathrm{u})>D_{\mu \mathrm{S}}(\mathrm{u}, \mathrm{v})$ for all nodes $u, v$ in $\mathrm{V}(\mathrm{G})$ where $\mathrm{D}_{\mu \mathrm{S}}(\mathrm{u}, \mathrm{v})$ is with respect to any non-empty fuzzy subset $\mathrm{S} \subseteq \mathrm{V}(\mathrm{G})$ and $k=2,3, \ldots . n$ and $n$ is the number of nodes.

C. If $G$ is a connected fuzzy graph

$\mathrm{R}_{\mu_{\mathrm{k}} \mathrm{G}}(\mathrm{G}) \leq \mathrm{DIAM}_{\mu_{\mathrm{k}} \mathrm{G}}(\mathrm{G}) \leq 2 R_{\mu_{\mathrm{k}} \mathrm{G}}(\mathrm{G})$

D. For every node u of a connected fuzzy graph $G(V, \sigma, \mu)$,

$D I A M_{\mu_{\mathrm{k}} \mathrm{G}}(\mathrm{G})-\mathrm{E}_{\mu_{\mathrm{k}} \mathrm{G}}(\mathrm{u}) \geq \mathrm{m}$

where $\mathrm{m}$ is any arbitrary non negative real number.

Published By:

Blue Eyes Intelligence Engineering
\& Sciences Publication

DOI: 10.35940/ijeat.D9010.049420

2159 (C) Copvriaht: All riahts reserved.

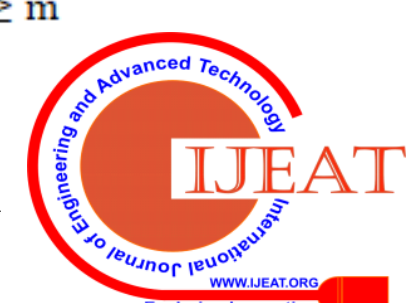


E. If a connected fuzzy graph $G$ is upper Steiner

$\mu_{\mathbf{k}}$-self-centred, then every node of $G$ is fuzzy upper Steiner $\mu_{\mathrm{k}}$ eccentric.

F. If a connected fuzzy graph $G$ is upper Steiner

$\mu_{\mathrm{k}}$-self-centred and for every node $u$ such that $u$ is a upper Steiner $\mu_{\mathrm{k}}$ eccentric node of another node $v$, then $v$ should be one of the upper Steiner $\mu_{\mathrm{k}}$ eccentric nodes of $u$.

\section{RELATION BETWEEN FUZZY STEINER $\mu$}

\section{DISTANCE AND FUZZY UPPER STEINER $\mu$ DISTANCE}

A. Observation: The following inequality is obvious from the definition of upper Steiner $\mu$-distance for any connected fuzzy graph $G$ and any non empty subset of nodes $S$ of $V(G)$.

$1 \leq d_{\mu G}(S) \leq D_{\mu G}(S)<\infty$.

\section{B. Theorem}

For every connected fuzzy graph $\mathrm{G}$ for which $\mathrm{r}_{\mu_{\mathrm{K}} \mathrm{G}}(\mathrm{G})=a$ and $\mathrm{R}_{\mu_{\mathrm{K}} \mathrm{G}}(\mathrm{G})=b$ where a,b are any real numbers, then $1 \leq a \leq b<\infty$.

Proof : Let $S$ be a non-empty subset of nodes with cardinality k. From Observation A (VII), $d_{\mu G}(S) \leq D_{\mu G}(S) .1 \leq a$ and $b<\infty$ are obvious.

$$
\begin{aligned}
& \text { Let } \mathrm{r}_{\mu_{\mathrm{K}} \mathrm{G}}(\mathrm{G})=a \text { and } \mathrm{R}_{\mu_{\mathrm{K}} \mathrm{G}}(\mathrm{G})=b \\
& a=\mathrm{r}_{\mu_{k} G}(\mathrm{G})=\min \left\{\mathrm{e}_{\mu_{\mathrm{r}} G}(\mathrm{u}) \backslash \mathrm{u} \in \mathrm{V}(\mathrm{G})\right\} \\
& =\min _{\mathrm{u} \in \mathrm{V}^{(}(G)}\left\{\max \left\{\mathrm{d}_{\mu S}(\mathrm{u}, \mathrm{v}) \backslash S \subseteq \mathrm{V}(\mathrm{G}),|\mathrm{S}|=\mathrm{k} \& \mathrm{u}, \mathrm{v} \in \mathrm{S}\right\}\right. \\
& \leq \min _{\mathrm{u} \in \mathrm{V}(\mathrm{G})}\left\{\max \left\{D_{\mu S}(\mathrm{u}, \mathrm{v}) \backslash S \subseteq \mathrm{V}(\mathrm{G}),|\mathrm{S}|=\mathrm{k} \& \mathrm{u}, \mathrm{v} \in \mathrm{S}\right\}\right. \\
& =\min \left\{\mathrm{E}_{\mu_{\mathrm{k}} \mathrm{G}}(\mathrm{u}) \mathrm{u} \in \mathrm{V}(\mathrm{G})\right\} \\
& =\mathrm{R}_{\mu_{\mathrm{k}} \mathrm{G}}(\mathrm{G})=b \text {. }
\end{aligned}
$$

\section{Theorem}

For every connected fuzzy graph $\mathrm{G}$ for which $\operatorname{diam}_{\mu_{\mathrm{k}} \mathrm{G}}(\mathrm{G})=a$ and $\operatorname{DIAM}_{\mu_{\mathrm{k}} \mathrm{G}}(\mathrm{G})=b$ where a,b are any real numbers, then $1 \leq a \leq b<\infty$.

Proof: Let $\mathrm{S}$ be a non-empty subset of nodes with cardinality k. From Observation A(VII), $d_{\mu G}(S) \leq D_{\mu G}(S)$. Let $\operatorname{diam}_{\mu_{\mathrm{k}} \mathrm{G}}(\mathrm{G})=a$ and $\operatorname{DIAM}_{\mu_{\mathrm{k}} \mathrm{G}}(\mathrm{G})=b$. Clearly $1 \leq a$ and $b<\infty$ are true.

$$
\begin{aligned}
& a=\operatorname{diam}_{\mu_{k} G}(G)=\max \left\{e_{\mu_{k} G}(\mathrm{u}) \backslash \mathrm{u} \in \mathrm{V}(\mathrm{G})\right\} \\
& =\max _{\mathrm{uEV}(G)}\left\{\max \left\{\mathrm{d}_{\mu S}(\mathrm{u}, \mathrm{v})|S \subseteq \mathrm{V}(\mathrm{G}),| \mathrm{S} \mid=\mathrm{k} \& \mathrm{u}, \mathrm{v} \in \mathrm{S}\right\}\right. \\
& \leq \max _{\mathrm{u} \in \mathrm{V}(\mathrm{G})}\left\{\max \left\{D_{\mu S}(\mathrm{u}, \mathrm{v})|S \subseteq \mathrm{V}(\mathrm{G}),| \mathrm{S} \mid=\mathrm{k} \& \mathrm{u}, \mathrm{v} \in S\right\}\right. \\
& =\max \left\{\mathrm{E}_{\mu_{k} \mathrm{G}}(\mathrm{u}) \mathrm{u} \in \mathrm{V}(\mathrm{G})\right\} \\
& =\operatorname{DIAM}_{\mu_{\mathrm{K}} \mathrm{G}}(\mathrm{G})=b
\end{aligned}
$$

\section{APPLICATION}

The fuzzy Steiner $\mu$ distance has application in many communication networks.

\section{Table 6}

\begin{tabular}{|l|l|l|l|l|l|}
\hline \multicolumn{3}{|l|}{ Roadways Between Two Locations } & $\begin{array}{c}\text { Dist. in } \\
\mathrm{km}\end{array}$ & $\begin{array}{c}\text { Vehicles } \\
\text { Passing in an } \\
\text { Hour }\end{array}$ & $\begin{array}{c}\text { Arc } \\
\text { Weight }\end{array}$ \\
\hline $\mathrm{R}_{1}$ & Market & Bustand & $0.5 \mathrm{~km}$ & 100 & 0.33 \\
\hline $\mathrm{R}_{2}$ & Bustand & Hospital & $3.5 \mathrm{~km}$ & 250 & 0.83 \\
\hline $\mathrm{R}_{3}$ & Market & Hospital & $3.8 \mathrm{~km}$ & 230 & 0.77 \\
\hline $\mathrm{R}_{4}$ & Police station & Market & $0.3 \mathrm{~km}$ & 67 & 0.22 \\
\hline $\mathrm{R}_{5}$ & Police station & Fun Mall & $1.8 \mathrm{~km}$ & 112 & 0.37 \\
\hline $\mathrm{R}_{6}$ & Mall & Harbour & $1 \mathrm{~km}$ & 98 & 0.32 \\
\hline $\mathrm{R}_{7}$ & Harbour & College & $5 \mathrm{~km}$ & 80 & 0.27 \\
\hline $\mathrm{R}_{8}$ & Hospital & College & $2.3 \mathrm{~km}$ & 300 & 1 \\
\hline $\mathrm{R}_{9}$ & School & College & $2.6 \mathrm{~km}$ & 280 & 0.93 \\
\hline $\mathrm{R}_{10}$ & Bustand & Harbour & $1.2 \mathrm{~km}$ & 200 & 0.67 \\
\hline
\end{tabular}

We can consider a traffic network problem. There are 8 major locations in an area such as bustand,hospital, mall, school, college, harbour,market and police station.There are roadways connecting these facilities.A sample data is given in table 6.This can be modelled into a fuzzy graph with locations as nodes and the roadways connecting the facility locations as arcs given in fig 7 . Arc weight for roadway $\mathrm{R}_{8}$ with maximum number of vehicles(300) is given the maximum membership value 1.For the other roadways, Arc weight $=\frac{\text { Number of vehicles }}{300}$

Let $\mathrm{S}=\{$ bustand,hospital,college,harbour $\}$.The minimum Steiner fuzzy tree of $S$ which gives the Steiner $\mu$-distance is the shortest route that connecting all the locations in $\mathrm{S}$ with more traffic shown in fig 8.The maximum Steiner fuzzy tree of $S$ which gives the upper Steiner $\mu$-distance is the shortest route that connecting the locations in $\mathrm{S}$ with less traffic given in fig 9 .

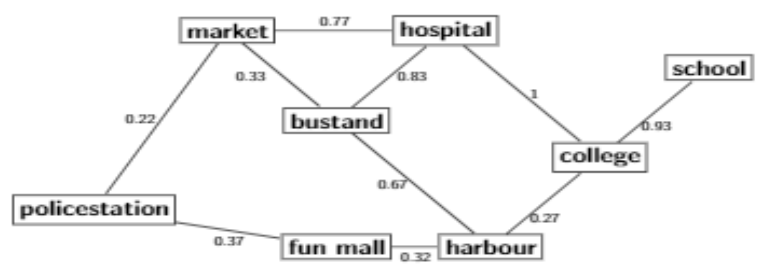

Figure 7

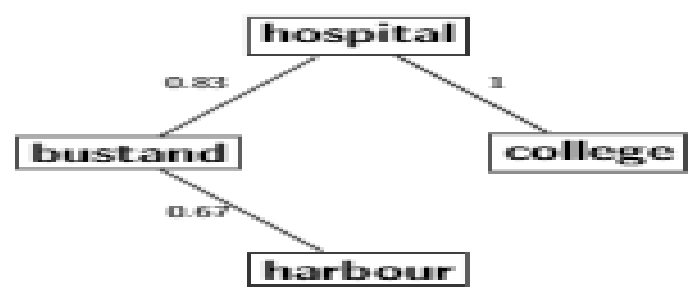

Figure 8

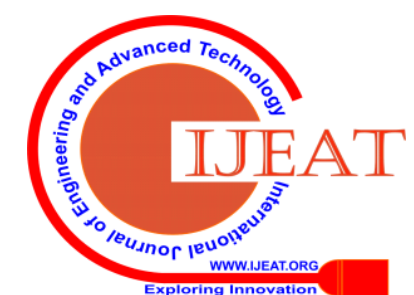




\section{Steiner $\boldsymbol{\mu}$ Distance in Fuzzy Graphs with Application}

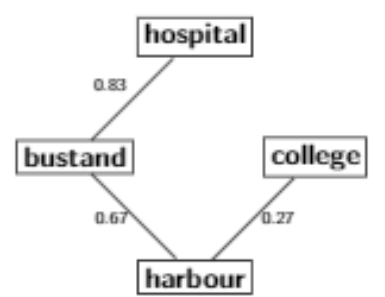

Figure 9

Steiner $\mu$-distance of $\mathrm{S}=3.69$

Upper Steiner $\mu$-distance of $S=6.39$.

\section{RESULT AND DISCUSSION}

Another real life application of Steiner and upper Steiner $\mu$ distances is a message transmitting network. Suppose a message transmitting network with processors, can be modelled into a fuzzy graph with processors as nodes and link between two processors as arcs and message transmitting speed between the processors as arc weights. The reciprocal of arc weight denotes the message flow rate between the processors. Here the Steiner $\mu$ distance of some $\mathrm{k}$ processors gives the net message flow rate of minimal fast communicating link containing these processors and fuzzy upper Steiner $\mu$ distance gives the net message flow rate of minimal slow communicating link containing these $\mathrm{k}$ processors.

\section{CONCLUSION}

In this article we have introduced and scrutinized the similar properties of Steiner $\mu$ distance and upper Steiner $\mu$ distances in fuzzy graphs by merging the Steiner distance and $\mu$ distance with a real life application. These distances also have application background in various communication networks like telecommunication networks, radio stations message transmitting networks, channel networks, radio stations, transports, wireless mobile Ad-hoc networks..etc. and are used in network analysis.

\section{REFERENCES}

1 K.R. Bhutani and A. Rosenfeld, Strong arcs in fuzzy graphs, Information Sciences,152(2003), 319-322.

2 V.Mythili, M.Kaliyappan and S.Hariharan, A Review of fuzzy graph theory, International Journal of Pure and Applied Mathematics, Volume 113,No 12 2017,187-195.

3 Peter Dankelmann, Henda C. Swarta and Ortrud R. Oellermannb, On the average Steiner distance of graphs with prescribed properties, Discrete Applied Mathematics (1997), 91-103.

4 M.S Sunitha and Sunil Mathew, Fuzzy Graph Theory: A Survey, Annals of pure and applied mathematics,(2013),92-110

5 M.P.Sunil and J.Suresh Kumar,On Fuzzy Distance in Fuzzy Graphs, International Journal of Mathematics and its Applications, 8(1) 2020,89-93.

6 Yashwant Vaishnaw and Sanjay Sharma, Some new approaches of fuzzy graph, IOSR Journal of Mathematics,(2016), 109-112Books:

7 John N.Moderson,Premchand S.Nair,Fuzzy Graphs and Hypergraphs,Physica-Verlag,A Springer Verlag Company,Newyork.

8 A. Rosenfeld, Fuzzy graphs, In Fuzzy Sets and their Application to Cognitive and Decision Processes, Academic Press, (1975).

9 Sameena Kalathodi,Sunitha M.S, Distance in Fuzzy Graphs, Lambert Academic Publishing. Thesis:

10 Yaping Mao, School of Mathematics and Statistics, Qinghai Normal University, Xining, Qinghai 810008, China, Steiner Distance in Graphs-A Survey,(2017).

J.Jenit Ajitha got UG degree from St.Mary's College,Thoothukudi, Tamil nadu. She got PG and MPhil degree from St.Xavier's College(Autonomous), Palayamkottai, Tamilnadu. She attended many conferences and presented few papers in various conferences.She is currently working as an Assistant Professor in St.Mary's College(Autonomous), Thoothukudi and doing Ph.D(part-time) under Manonmaniam Sundaranar University,Tirunelveli. 